\title{
Report of the 17th European Stroke Conference, Nice, May 13-16, 2008
}

\author{
J.P. Mohr \\ Neurological Institute, Columbia University College of Physicians and Surgeons, New York, N.Y., USA
}

No less than 3,665 attendees from 83 countries arrived in Nice for the 17th European Stroke Conference, held at the Acropolis Palais de Congrès et des Expositions facility (in Nice, not Greece). This number continues the trend of increasing attendance (an increase of almost 1,000 people compared to the Glasgow meeting in 2007), reflecting the high profile of the European Stroke Conference. In fact, 165 web pages were needed to detail the program.

On the first day, 13 May, a repeat of the increasingly popular workshops and teaching sessions were held, as well as an all-day 2nd TIA Satellite Symposium, chaired by P. Amarenco, and featuring G. Donnan, P. Kelly, P. Sandercock, S. Coutts, M.G. Hennerici, H.-C. Diener, and A. Schwartz, finishing in the afternoon with P.M. Rothwell, A. Buchan, P. Amarenco, and summarized by M.G. Hennerici. The entire gamut of TIA issues was discussed. During the same day, the 2nd Nursing and AHP Day was held for stroke nurses and allied personnel. In the side rooms, 10 individual courses were held on stroke in the newborn and stroke in the elderly, clinical syndromes, poststroke complications and stroke outcome, MRI, and even 'How to write a good article'. That evening, Jean-Louis Mas welcomed a large crowd, Program Committee chair M.G. Hennerici, and Scientific Committee chair J.M. Ferro, on behalf of his French colleagues, in the Apollo conference auditorium of the venue.
The first official day of the conference, 14 May, opened with parallel sessions held in no less than 7 rooms, on acute stroke, stroke and infections, risk factors and their management, and ditto for diabetes. These sessions were finished in time for general attendance at the highlights of the meeting. First, after an elegant introduction by J. van Gijn, M.G. Bousser, the Johann Jacob Wepfer awardee, gave a wide-ranging presentation, citing the role in research and effect of therapies for women on almost all of the subjects covered. These subjects spanned a scope of over 30 years, starting from the initial TIA trials run by H.J.M. Barnett (including the rarely cited 1958 reference on aspirin benefit by Lawrence Craven in Mississippi Valley Medicine); CADASIL was reviewed, emphasizing the thick arteries and accompanying rigidity. Two other subjects, hemicraniectomy and closure for patent foramen ovale, were given thoughtful analyses of the clinical outcomes. None present were in doubt as to her mastery (perhaps one should say 'mistressy') of the subjects covered, and she finished to thunderous applause.

What followed was one of the highlights of the conference, i.e. presenting latest news from large clinical trials. Three of those were from the PRoFESS trial (Prevention Regimen for Effectively Avoiding Second Strokes). Sponsored by Boehringer-Ingelheim and hailed as the largest worldwide study of secondary stroke prevention, the PRoFESS trial randomized over 20,000 patients from 695

\section{KARGER}

Fax +4161306 1234 E-Mail karger@karger.ch www.karger.com
(C) 2008 S. Karger AG, Basel

$1015-9770 / 08 / 0263-0335 \$ 24.50 / 0$

Accessible online at:

www.karger.com/ced
Prof. Jay P. Mohr

Neurological Institute, Columbia University College of Physicians and Surgeons 701 W. 168th Street

New York, NY 10029 (USA)

Tel. +1 212305 8033, Fax +1 212305 5796, E-Mail jpm10@columbia.edu 
worldwide sites who had had initial ischemic stroke for an observational period of up to 4 years. The trial compared the safety and efficacy of $25 \mathrm{mg}$ aspirin/200 mg extended-release dipyridamole $\left(\right.$ Aggrenox $^{\circledR}$, Asasantine ${ }^{\circledR}$ ) with clopidogrel, and of telmisartan (Micardis ${ }^{\circledR}$ ) with placebo, atop any ongoing therapy for hypertension. This three-part presentation of the PRoFESS trial featured the co-investigators R.L. Sacco, H.-C. Diener and S. Yusuf. Some of the results had leaked out from the investigator meeting the day before despite requests for embargo, but the presentations were extremely clear: in brief (and to avoid presenting any quantitative data pending publication), no difference could be found in the comparison of low-dose aspirin and long-acting dipyridamole or clopidogrel for the primary outcome of recurrent stroke. The risk of stroke, myocardial infarction or vascular death was identical in the two treatment groups. The study was unable to conclude noninferiority; no interaction was observed between telmisartan and placebo. Major hemorrhage and headache were slightly more frequent in the low-dose aspirin and long-acting dipyridamole arm, but the two treatments were comparable in the occurrence of myocardial infarction, a comparison hitherto untested in a clinical trial. No neuroprotective effects were found over time or at the end of the trial. For the telmisartan part of the trial, no significant differences were found between telmisartan and placebo in the primary outcome of recurrent stroke, or the secondary outcomes of stroke, myocardial infarction, vascular death, or new or worsening of congestive heart failure. It was suggested that the effects of this angiotensin receptor blocker may be greater for those treated for more than 6 months.

The large clinical trial session was continued with an update on EVA-3S (NCT00190398) presented by J.L. Mas. The trial had a noninferiority plan for the risk of stroke within 30 days of the procedure, and thereafter for a longterm follow-up. The study was balanced for age, gender, diabetes mellitus, prior stroke, prior myocardial infarction, therapy with antiplatelets, antihypertensives, lipidlowering agents, and nonsmokers; the distribution of lesions was almost all $>70 \%$. Those over age 70 had more periprocedural events, but thereafter the 4 -year event rates compared favorably with those after endarterectomy. Of special interest was the lower 30-day stroke rate among the $39 \%$ of cases in whom stenting was performed by those in training, under supervision, compared with those deemed experienced.

P.A. Ringleb followed with the 2-year results of the SPACE (Stent-Protected Percutaneous Angioplasty of the
Carotid vs. Endarterectomy) study. The outcomes for the two procedures overlapped for 2-year outcomes of mortality, any stroke, and any ipsilateral stroke, but restenosis was more frequent in the stent arm.

The session ended with a report by D.F. Hanley on the three outcomes of the CLEAR trial (clot lysis, safety, and 30-day outcome). This trial, involving r-tPA given via an external ventricular device, rated 6-month outcomes for 52 subjects admitted within $12 \mathrm{~h}$ of onset and receiving r-tPA up to $60 \mathrm{~h}$ from onset, and showed outcomes sufficiently encouraging as to propose a phase III clinical trial.

Posters were available for review during the lunch break on the first as well as on the second day.

In the afternoon, there were discussions in the Apollo auditorium on the implications of the current clinical trial data by P. Gorelick, A. Algra, S. Yusuf, P. Bath, and G. Hankey. Later, in side rooms, acute stroke concepts, stateof-the-art vascular biology, heart-brain/venous diseases, and prognostic predictors were the subjects of presentations.

Thursday, 15 May, featured a morning plenary session on the subject of stroke care in Europe. Presenters included T. Truelsen (Denmark), T. Tsiskaridze (Georgia), D. Leys (France) and B. Norrving (Sweden). Results of a random European survey showed that (1) less than 10\% of European hospitals admitting acute stroke patients have a facility for such treatment; (2) $85 \%$ of stroke patients are not treated in an appropriate unit; (3) there are differences between countries, and (4) r-tPA is underutilized in clinical practice.

An even larger range of presentations was conducted throughout the day in side rooms. The correspondent was unable to do more than a survey of some of these specific presentations, mainly due to the concurrent workshop on the ARUBA trial. Fortunately, the main program contained detailed abstracts for these platform presentations.

Many were almost relieved to find the scope and number of subjects to be a bit smaller on the last day, Friday 16 May. In the Apollo auditorium, a joint session of the European Society of Cardiology and the European Stroke Conference provided presentations of stroke mechanisms. C. Schneider discussed the metabolic syndromes, noting that $1,500 \mathrm{kcal}$ a week greatly improves prognosis. Brisk walking 30-50 min several times per week, especially worthwhile for diabetics, as often as 3-4 h a week, could result in a mortality risk reduction of $50 \%$. The session ended with a summary from P. Amarenco on TIAs. He proposed a 1-hour definition for TIA versus stroke, 
and suggested a simple dichotomy based on time from the event: same day or continuing symptoms, go to a stroke unit; if the symptoms are gone, go to a TIA clinic. Moreover, he reviewed the ABCD acronym from Rothwell, and repeated a proposal from the Round Table of the 1st TIA symposium in Paris 2006 that TIA should be replaced by 'acute cerebrovascular syndrome'; however, whether TIA can be replaced as a term remains to be seen.

Parallel presentations were conducted in 5 rooms, covering intracerebral and subarachnoid hemorrhages, vascular neurosurgery, etiology of stroke, meta-analyses and review papers, and symposia. In the hemorrhage sessions, Marti-Fabregas et al. (Spain) noted that neurological worsening correlated with hematoma enlargement. Hematoma enlargement of $>33 \%$ was reported in almost half of the patients seen and imaged within $6 \mathrm{~h}$ of onset. The clinical evidence of worsening was most often seen in those whose enlargement was at least $46 \%$. Hemorrhagic features of the reversible cerebral vasoconstriction syndrome (so-called Call-Fleming syndrome) were described by Ducros et al. (France). R. Brown et al. from the Mayo Clinic (USA) reviewed the clinical recommendations for aneurysm management. Demchuk et al. (Cana- da) reported on the increasingly popular search for a 'spot sign'. Its prediction for hematoma expansion was highest for those imaged in the 2-hour time frame. The population-based Scottish AVM study and the Oxfordshire project demonstrated in both populations a large increase in severity from primary parenchymatous brain hemorrhage versus that from arteriovenous malformation, with no differences found for hematoma volume or ventricular extension.

Satellite symposia held during the conference included antiplatelet strategies, stroke registries and data banks, management of ischemic stroke (Boehringer-Ingelheim sponsor), optimized stroke care for readmission reduction in Europe (BMS sponsor), stroke research priorities for the next decades (Ferrer Group sponsor), and even one for Francophones (French Neurovascular Society).

The correspondent regrets being unable to survey the full range of presentations and posters, having concentrated on those presentations in the main (Apollo) auditorium, most of which were not accompanied by printed summaries. It is hoped those who find themselves not cited will take no offense, expecting a bigger impact when the work appears in peer-reviewed print. 